\title{
Smoking-related knowledge and attitudes of senior Australian medical students
}

\begin{abstract}
Objective-To assess the smoking-related knowledge and attitudes of senior medical students and to compare knowledge and attitude changes in students exposed to four different smoking cessation skills training interventions.

Design-A survey questionnaire, assessing knowledge and attitudes, was adminis-

specific intervention strategies and cessation practices is required to develop competence in this area and to maximise the chances of new medical graduates fully using the opportunities available to them.

(Tobacco Control 1996;5:271-279)

Keywords: cessation skills training; smoking-related knowledge; medical students; Australia.
\end{abstract} tered pre- and post-intervention for each of the four intervention conditions.

Subjects-A cohort of 219 fifth-year medical students at the University of Sydney.

Interventions-Students were randomised into one of four intervention conditions: (1) a traditional didactic lecture mode (control group); (2) the use of role plays and audiotaped feedback; (3) role plays with peer feedback; and (4) video feedback.

Main outcome measures-Knowledge on morbidity and mortality associated with smoking, intervention strategies, intervention effectiveness, and cessation practices; anticipated clinical behaviour related to smoking; and attitudes towards medical practitioner involvement in smoking cessation.

Results-Smoking knowledge was significantly greater at post-test (mean unweighted scores of $69 \%$ before and $74 \%$ after intervention). All groups had improved knowledge levels at post-test. However, after controlling for pre-test differences, the control group, video feedback, and peer feedback groups were found to have improved significantly over the audio feedback group. Scores were higher on items related to morbidity and mortality and intervention effectiveness than for items on intervention strategies and cessation practices. Positive student attitudes towards their role in smoking cessation were also found. There was an almost universally held view that doctors can have a significant impact on reducing smoking levels. Although most students perceived smoking intervention to be a worthwhile activity, they remained pessimistic about the ease with which patients' smoking behaviour could be changed.

Conclusions-Positive smoking cessation knowledge changes can be readily achieved through training. However, specific smoking cessation training is needed for medical trainees to develop appropriate skills and strategies. Attention to particular weaknesses related to

\section{Introduction}

There is increasing interest in using a variety of access points to address smoking cessation. ${ }^{12}$ Primary care physicians, in particular, have the potential to play an effective, but as yet underused role as smoking cessation agents. ${ }^{34}$ Correspondingly, increasing attention has been directed towards medical students as future medical practitioners and potential agents in smoking cessation. ${ }^{5}$ Ensuring that medical students have adequate knowledge and skills for engaging in smoking cessation is essential. ${ }^{6}$

To date, numerous surveys have been carried out in countries across the globe to assess medical students' smoking practices and their knowledge of smoking-related health issues and intervention strategies. ${ }^{79}$ Prevalence of smoking by medical students varies widely according to country and cultural setting. ${ }^{10-18}$ However, in most English-speaking countries prevalence is low to very low. ${ }^{71213}$ Studies of medical students' smoking knowledge levels have revealed major deficits. ${ }^{711}$ Such findings have increased concern that if medical students and newly graduating practitioners are to be effective in any capacity as agents for smoking cessation, then increased efforts need to be directed to the development of knowledge and skills at the undergraduate level of training. ${ }^{7810}$ Without sufficient and appropriate attention directed to young trainees it is unlikely that they will fulfil their potential later with regard to smoking cessation. dents is highlighted when the potential of medical practitioners is examined. Medical practitioners have ample opportunity for smoking cessation intervention-they see it as part of their role, they can be very effective, ${ }^{19} 20$ and patients perceive them to be a desirable source of such information. ${ }^{2122}$ From a public health perspective, it has been argued that the impact of a high percentage of doctors encouraging their patients to stop smoking could be significant. It has been estimated that if only $3 \%$ of doctors advised $25 \%$ of their smoking patients to stop smoking, and $5 \%$ of these patients did stop, there would be over 1000 more ex-smokers each year in Australia. ${ }^{23}$
The importance of focusing on medical stu- 
Despite this potential, only limited efforts have been made to train adequately current and future medical practitioners in smoking cessation. Not surprisingly, medical practitioner activity in this area is notably weak. Although most general practitioners claim to routinely ask patients about their smoking behaviour, ${ }^{24}{ }^{25}$ there is evidence that intervention rates are quite low, ${ }^{19}{ }^{21}$ and that ability to detect patients who smoke is limited. ${ }^{22}$

There have been few efforts to identify the factors that may contribute to poor intervention rates. ${ }^{26}$ It has been speculated that it may be due in part to insufficient knowledge about intervention strategies. For instance, when medical practitioners do intervene, their smoking cessation counselling methods are often less than ideal. Limitations include failure to: discuss obstacles to quitting; set a quit date; prescribe nicotine gum; schedule follow-up visits; or provide self-help material. ${ }^{27}$ Failure to offer effective interventions may also be due to a lack of perceived self-efficacy. ${ }^{28}$ Most medical practitioners appear not to consider their intervention attempts to be very effective or likely to lead to success. ${ }^{24}{ }^{27}{ }^{29}$ However, practitioners who feel prepared, confident, and successful have been found to use more of the effective smoking cessation counselling techniques than those who do not. $^{27}$

Lack of training in smoking cessation counselling and the perceived ineffectiveness of physician's advice have been identified as important barriers. ${ }^{21}$ Evidence suggests that medical practitioners' knowledge of smoking cessation strategies and attitudes towards cessation counselling may be important factors in determining the routine use of effective intervention strategies. Training medical students in these strategies is therefore considered essential.

Such findings highlight the need for more and better training of both current and future medical practitioners at both the undergraduate and postgraduate levels. Moreover, little is known of the relative efficacy of teaching medical students about smoking cessation using different educational strategies. If optimal clinical behaviour is considered desirable in this area, then similarly, optimal educational strategies are imperative. Information about medical practitioners' and medical students' knowledge and attitudes can highlight areas of concern and assist in curriculum development for undergraduate and continuing medical education in smoking cessation, and thus enhance the potential for medical practitioners to function as effective agents in smoking cessation. Our study was therefore undertaken as part of a trial examining strategies to improve smoking cessation skills. ${ }^{30}$

The data reported here cover senior medical students' knowledge of and attitudes towards smoking cessation intervention and the impact of different modes of educational delivery. Specifically, the aims of the study were firstly, to determine the knowledge and attitudes of fifth-year undergraduate medical students with regard to smoking cessation intervention, and secondly, to compare changes in medical students' knowledge and attitudes across four different skills training groups.

\section{Methods}

SAMPLE

Participants were a cohort of 219 fifth-year medical students from the University of Sydney. As part of their usual clinical training, students in each year are divided into four term groups. Allocation to groups is random with no apparent systematic differences. Within these groups students complete a series of 10 -week term rotations through four different disciplines. This study was conducted during the term in which drug and alcohol teaching is an integral part.

\section{PROCEDURE}

We conducted a knowledge and attitudes survey as part of a randomised, controlled trial examining the relative effectiveness of four different educational programmes in teaching smoking cessation skills to undergraduate medical students. The trial consisted of a block randomisation (by term) of students to either a control group or one of three study conditions. The four experimental groups were: (1) a traditional didactic lecture mode (control group); (2) the use of role plays and audiotaped feedback; (3) role plays with peer feedback; (4) video feedback. There were approximately 50 students in each of the four groups. Each group received a total of three hours of smoking cessation instruction consisting of essentially the same content and approaches to smoking cessation, with only the instructional mode differing among the four groups. Each intervention group received a different educational package on smoking cessation as they rotated, on a term by term basis, through year 5 of their medical course. Experimental groups differed with regard to the type of training techniques that were used to teach smoking cessation skills. However, all groups received identical handout literature, and a core lecture was presented to each group. The core lecture covered the burden of illness associated with smoking, and the potential for intervention by medical practitioners. In the standard teaching group these topics were covered in more detail and supplemented by a video. Full details of the skills training component of the study examining students' smoking cessation intervention skills have been reported elsewhere. ${ }^{30}$

The four groups consisted of:

(1) A standard teaching presentation-the control group received a standard three-hour didactic teaching presentation on smoking prevalence, physiological, and other effects of smoking, and the public health implications of smoking. The lecture content encouraged the participation of doctors in smoking cessation. This group received no specific lectures on intervention techniques with or without counselling skills for smoking and was not involved with smoking-related group work or role plays. 
(2) Audio feedback--group 2 received a one-hour lecture on smoking and was also provided with pre-reading and instructions to produce a 10-minute, audiotaped doctor-patient interview on smoking cessation. Faculty feedback on the students' performances in the audiotaped interviews was later provided through small, two-hour group tutorial sessions.

(3) Peer feedback group-group 3, in addition to the one-hour lecture and pre-reading package on smoking, participated in role plays of smoking intervention interviews over a two-hour period. Students worked in triads and alternatively role-played the doctor and patient and also assumed the role of observer. Peer feedback on intervention techniques was provided by the observer in each role play and was supervised by faculty staff. Students were encouraged to rate each others' performances.

(4) Video feedback group - group 4 received a one-hour lecture on smoking and a pre-reading package. Each student in this group also role-played smoking cessation interviews, which were videotaped. Feedback was given on students' performances in these videotaped interviews through small, two-hour long group sessions, in which faculty tutors provided individual feedback on the videotaped interviews.

PRE- AND POST-TEST ASSESSMENT

To assess the students' smoking knowledge and attitudes, a questionnaire was administered before the intervention at the beginning of term and again at the end of the term. The questionnaire was first given to the students immediately before the start of the teaching session. Approximately 10 weeks after the initial assessment, the instrument was administered as part of the post-test assessment of performance skills. It was not compulsory for students to complete this assessment, although they were strongly encouraged to participate.

\section{SURVEY INSTRUMENT}

A questionnaire, derived from existing instruments, ${ }^{34}$ and revised by a panel of experts in the areas of medical education and smoking cessation, was used in the study. The questionnaire took approximately 10-15 minutes to complete and contained a total of 48 knowledge and attitude items. In addition, the questionnaire included seven items of a biographical nature, such as age and gender; prior qualifications; training in smoking cessation, and intended career path. Students were assured that the questionnaire was confidential and would have no bearing on their overall academic assessment.

There were 32 knowledge questions related to: (a) morbidity and mortality associated with smoking; (b) intervention strategies; (c) intervention effectiveness, and (d) cessation practices. The knowledge questions were mostly presented in a true/false format, with some as multiple choice. The following are examples of the questions asked and the content covered.

Q. Smoking among pregnant women is associated with an increased risk of spontaneous abortion and fetal death.

$\mathrm{T} F$

Q. Getting a patient to set a specific day to stop smoking improves their chances of stopping.

$\mathrm{T} \mathrm{F}$

Q. Physician advice to stop smoking is twice as effective when combined with a follow-up visit.

$\mathrm{T} F$

Two additional questions sought information about anticipated clinical behaviour. One question asked respondents to "indicate the percentage of patients who were smokers they would detect in clinical practice." The second question enquired about "the percentage of patients whom they would routinely ask about their smoking." Responses to these two questions were recorded on a scale of $0-100 \%$ with $10 \%$ deciles marked.

The questionnaire also contained nine attitudinal questions formatted on a sevenpoint scale $(-3$ to +3$)$ with the end points labelled: "strongly disagree/strongly agree"; "very difficult/very easy"; or "do not require skills/require further skills". Three of the nine questions were related to general health promotion activities.

\section{SCORING}

Each correct answer was given a score of one point, and wrong answers were scored as zero. An overall knowledge score and an attitude score were calculated for each student on their pre-test and post-test performances. In addition, knowledge items were grouped into four categories: morbidity and mortality, smoking cessation intervention strategies, intervention effectiveness, and cessation practices-with mean scores calculated for each of these knowledge categories at pre-test and post-test.

For the nine attitude items, the rating scale of -3 to +3 was converted to a score from 1 to 7 , with values ranging from the most negative (that is, 1) to the most positive (7). The scale was inverted for two items to ensure consistency of the scale's direction.

\section{ANALYSIS}

The data were analysed to determine whether there were any significant differences in preand post-test smoking knowledge and smoking attitude scores for three training strategies providing feedback (audio feedback, peer feedback, and video feedback) compared with a control group who received no feedback. Smoking knowledge was further examined by four subcategories: morbidity/mortality, intervention strategies, intervention effectiveness and cessation practices. Pre- and post-test scores were calculated for individuals who completed both questionnaires and these scores were used to analyse the effect of training.

Within-groups mean scores, at pre-test and post-test, for knowledge, knowledge categories, and attitude were analysed using paired $t$ tests. Difference scores were calculated for 
Table 1 Smoking knowledge scores by group

\begin{tabular}{llllll}
\hline & \multicolumn{3}{c}{ Pre-test } & & \multicolumn{2}{c}{ Post-test } \\
\cline { 2 - 3 } \cline { 5 - 6 } Groups & $\%$ & Mean $(S D)$ & & $\%$ & Mean (SD) \\
\hline & & & & \\
Group 1 (control group) & 72 & $23.1(2.24)$ & & 74 & \\
Group 2 (audio feedback) & 67 & $21.5(3.11)$ & & 72 & $23.6 \ddagger(1.67)$ \\
Group 3 (peer feedback) & 69 & $22.1(2.84)$ & & 75 & $22.9 \dagger(1.99)$ \\
Group 4 (video feedback) & 64 & $20.6^{\star}(3.04)$ & & 76 & $23.9+\ddagger(1.69)$ \\
All groups & 69 & $22.0(2.8)$ & & 74 & $24.2 \dagger \ddagger(2.19)$ \\
\hline
\end{tabular}

Maximum possible score $=32$.

*Significantly lower than the control group at pre-test $(P<0.01)$.

†Significantly increased scores at post-test $(P<0.05)$.

$¥$ Significantly different from the audio feedback group.

knowledge, knowledge categories, and attitude, and a between-groups analysis of variance was conducted to assess the effects of the training strategies. Pre-test scores were examined using an analysis of variance to determine whether groups differed on initial levels of knowledge and attitude. An analysis of covariance was then performed on post-test knowledge, knowledge categories, and attitude scores, with pre-test group mean scores used as a covariate. Scheffe tests were used to determine post hoc differences. Pearson's product moment was used to determine whether there were significant correlations between the knowledge and attitude scores of the groups at pre- and post-test.

\section{Results}

\section{DEMOGRAPHIC PROFILE}

A total of 173 students completed the questionnaire at pre-test (a response rate of $79 \%$ ) and 125 at post-test (a $72 \%$ retention rate). The average age of the sample was 22 years (range 21-44 years). Sixty-two per cent of the sample were male. Most students (87\%) did not possess previous professional qualifications, and most had not received specific training relevant to counselling patients on smoking cessation (94\%). Preferred career paths were general practice (15\%), physician training (internists) $(12 \%)$, surgery ( $9 \%)$, other $(16 \%)$, with most $(48 \%)$ unsure of their future career path. Four per cent of the sample reported that they were smokers, $9 \%$ were ex-smokers, and $87 \%$ were never-smokers. Of the smokers in the sample, nearly all described themselves as "light" smokers (fewer than 10 cigarettes a day).

Because of the level of confidentiality guaranteed to students, limited information was available on non-responders to make any useful comparisons between responders and non-responders.

\section{SMOKING KNOWLEDGE LEVEIS}

Table 1 shows pre- and post-test mean knowledge scores by condition and for the overall cohort. The mean pre-test knowledge score for the total sample was $69 \%$ with a mean raw score of 22.0 (maximum possible score $=32$ ) and a range of 14 to 28 . The post-test mean knowledge score was $74 \%$, with a mean raw score of 23.6 and a range of 20 to 29. A paired $t$ test of means found post-test knowledge scores to be significantly higher than pre-test scores $(t=-6.03, \mathrm{df}=99, \mathrm{P}=0.005)$.

All groups, except the control group, showed significantly increased knowledge scores at post-test: audio feedback group $(t=-2.26$, $\mathrm{df}=21, \quad \mathrm{P}=0.035)$, peer feedback group $(t=-3.87, \mathrm{df}=22, \mathbf{P}=0.001)$, and video feedback group $(t=-6.33, \quad \mathrm{df}=18$, $P=0.005$ ).

Analysis of variance on pre-test scores revealed the video feedback group's score to be significantly lower than the control group $(F=3.56, \mathrm{df}=3,96, \mathrm{P}<0.01)$. Analysis of variance using difference scores found the video feedback group's scores to be significantly higher than those of the audio feedback group or the control group $(F=5.55, \mathrm{df}=3,96, \mathrm{P}=0.001)$. After adjusting for pre-test differences, an analysis of covariance found the peer feedback group, the video feedback group, and the control group to have significantly higher scores than the audio feedback group $(F=3.20, \quad \mathrm{df}=3,95$, $P=0.02)$.

\section{SPECIFIC SMOKING KNOWLEDGE CATEGORIES}

Knowledge items were grouped into one of the following four categories: morbidity/mortality, intervention strategies, intervention effectiveness, and cessation practices. Mean scores were calculated for each of these categories at pre-

Table 2 Smoking knowledge scores by category

\begin{tabular}{|c|c|c|c|c|c|c|c|c|c|c|c|c|c|c|c|c|}
\hline \multirow[b]{3}{*}{ Group } & \multicolumn{4}{|c|}{$\begin{array}{l}\text { Morbidity/mortality } \\
(12 \text { items } ; \max =12)\end{array}$} & \multicolumn{4}{|c|}{$\begin{array}{l}\text { Intervention strategies } \\
(4 \text { items; } \max =4)\end{array}$} & \multicolumn{4}{|c|}{$\begin{array}{l}\text { Intervention effectiveness } \\
(9 \text { items; } \max =9)\end{array}$} & \multicolumn{4}{|c|}{$\begin{array}{l}\text { Cessation practices } \\
(7 \text { items; } \max =7)\end{array}$} \\
\hline & \multicolumn{2}{|c|}{ Pre-test } & \multicolumn{2}{|c|}{ Post-test } & \multicolumn{2}{|c|}{ Pre-test } & \multicolumn{2}{|c|}{ Post-test } & \multicolumn{2}{|c|}{ Pre-test } & \multicolumn{2}{|c|}{ Post-test } & \multicolumn{2}{|c|}{ Pre-test } & \multicolumn{2}{|c|}{ Post-test } \\
\hline & $\%$ & Mean (SD) & $\%$ & Mean (SD) & $\%$ & Mean (SD) & $\%$ & Mean (SD) & $\%$ & Mean (SD) & $\%$ & Mean (SD) & $\%$ & Mean (SD) & $\%$ & Mean $(S D)$ \\
\hline $\begin{array}{l}\text { Group } 1 \text { (control } \\
\text { group) }\end{array}$ & 90 & $10.8(1.11)$ & 92 & $11.1(0.93)$ & 67 & $2.7(0.83)$ & 74 & $2.9(0.73)$ & 64 & $5.7(0.97)$ & 65 & $5.8(1.07)$ & 55 & $3.9(1.38)$ & 54 & $3.8(0.96)$ \\
\hline $\begin{array}{l}\text { Group } 2 \text { (audio } \\
\text { feedback) }\end{array}$ & 81 & $9.7^{\star}(1.32)$ & 91 & $11.0(0.89)$ & 68 & $2.7(0.55)$ & 69 & $2.8(0.75)$ & 64 & $5.8(1.15)$ & 70 & $6.3(0.88)$ & 46 & $3.2(1.41)$ & 42 & $2.9(0.92)$ \\
\hline $\begin{array}{l}\text { Group } 3 \text { (peer } \\
\text { feedback) }\end{array}$ & 86 & $10.3(1.28)$ & 92 & $11.0(0.98)$ & 74 & $3.0(0.57)$ & 79 & $3.1(0.71)$ & 59 & $5.3(1.28)$ & 70 & $6.3(0.89)$ & 50 & $3.5(1.59)$ & 49 & $3.4(0.88)$ \\
\hline $\begin{array}{l}\text { Group } 4 \text { (video } \\
\text { feedback) }\end{array}$ & 74 & $8.9^{\star}(2.11) \ddagger$ & 91 & $11.0(0.91)$ & 70 & $2.8(0.86)$ & 72 & $2.9(0.74)$ & 60 & $5.4(0.96)$ & 77 & $7.0 \$(1.22)$ & 50 & $3.5(1.39)$ & 48 & $3.4(1.34)$ \\
\hline All groups & 84 & $10.1(1.57)$ & 92 & $11.0 \dagger(0.92)$ & 70 & $2.8(0.72)$ & 74 & $3.0(0.73)$ & 62 & $5.6(1.10)$ & 70 & $6.3+(1.07)$ & 51 & $3.5(1.45)$ & 49 & $3.4(1.05)$ \\
\hline
\end{tabular}


Table 3 Smoking knowledge scores. (Selected knowledge items where increases in knowledge were found.)

\begin{tabular}{|c|c|c|c|}
\hline & & Pre-test (\%) & Post-test (\%) \\
\hline$\overline{\mathrm{Q} 8}$ & $\begin{array}{l}\text { Evidence suggests that providing written information } \\
\text { significantly improves the efficiency of smoking } \\
\text { cessation advice. }\end{array}$ & 84 & 97 \\
\hline Q 9 & $\begin{array}{l}\text { Cigarette smoking is the single most preventable source } \\
\text { of premature morbidity and mortality. }\end{array}$ & 92 & 100 \\
\hline Q 10 & $\begin{array}{l}80-90 \% \text { of chronic obstructive pulmonary disease } \\
\text { morbidity and mortality is associated with smoking. }\end{array}$ & 91 & 96 \\
\hline Q 11 & $\begin{array}{l}10 \text { Years after giving up smoking the risk of death from } \\
\text { coronary heart disease for former smokers is } \\
\text { approximately the same as for people who have never } \\
\text { smoked. }\end{array}$ & 71 & 86 \\
\hline Q 12 & $\begin{array}{l}\text { Smoking among pregnant women is associated with an } \\
\text { increased risk of spontaneous abortion and fetal } \\
\text { death. }\end{array}$ & 88 & 96 \\
\hline \multirow[t]{4}{*}{ Q 14} & Physician advice to stop smoking: & & \\
\hline & $\begin{array}{l}\text { (a) is twice as effective when combined with a } \\
\text { follow-up visit }\end{array}$ & 79 & 92 \\
\hline & (b) results in a one-year quit rate of about $40 \%$ & 26 & 35 \\
\hline & $\begin{array}{l}\text { (c) is more effective in patients who have a } \\
\text { smoking-related illness. }\end{array}$ & 85 & 98 \\
\hline Q 16 & $\begin{array}{l}\text { Nicotine gum is most effective for patients who } \\
\text { demonstrate evidence of high nicotine dependency. }\end{array}$ & 78 & 92 \\
\hline Q 19 & $\begin{array}{l}\text { Getting a patient to set a specific day to stop smoking } \\
\text { improves their chances of stopping. }\end{array}$ & 82 & 91 \\
\hline Q 22 & $\begin{array}{l}\text { Doctors can have a significant impact on the reduction } \\
\text { in numbers of smokers. }\end{array}$ & 89 & 97 \\
\hline Q 23 & $\begin{array}{l}\text { Patients' first preference for assistance to stop smoking } \\
\text { is their doctor. }\end{array}$ & 66 & 91 \\
\hline \multirow[t]{5}{*}{ Q 29} & \multicolumn{3}{|c|}{ Smoking increases the risk of developing cancer in the following organs: } \\
\hline & Lung, larynx, oral cavity & $>95$ & 100 \\
\hline & Esophagus, bladder & 90 & 97 \\
\hline & Kidney & 32 & 58 \\
\hline & Pancreas. & 60 & 77 \\
\hline \multicolumn{4}{|c|}{ Decreases in incorrect answers were noted in the following questions: } \\
\hline \multirow[t]{2}{*}{ Q 14} & Physician advice to stop smoking: & & \\
\hline & $\begin{array}{l}\text { (d) is provided to more than } 75 \% \text { of smokers in a } \\
\text { primary care practice. }\end{array}$ & 28 & 12 \\
\hline Q 17 & $\begin{array}{l}\text { Nicotine gum can be used to help patients cut down } \\
\text { the number of cigarettes they smoke. }\end{array}$ & 92 & 74 \\
\hline Q 20 & $\begin{array}{l}\text { Doctors detect more than } 80 \% \text { of their patients who } \\
\text { smoke. }\end{array}$ & 35 & 9 \\
\hline
\end{tabular}

and post-test as shown in table 2. For the group as a whole, paired $t$ tests revealed significant increases in knowledge scores for morbidity/mortality $\quad(t=-5.92, \quad \mathrm{df}=99$, $\mathrm{P}=0.0005)$ and intervention effectiveness $(t=-4.82, \mathrm{df}=99, \mathrm{P}=0.0005)$.

A between-groups analysis using pre-test scores for the four knowledge categories found significant differences on morbidity/mortality ( $F=7.69$, df $=3,96, \mathrm{P}=0.0001$ ), with the control group having a higher mean score (10.8) than either the audio feedback group (9.7) or the video feedback group (8.9). The peer feedback group also had a higher group mean score at pre-test (10.3) than the video feedback group. No other pre-test differences were found on the knowledge subcategories.

For each knowledge category a betweengroups analysis of variance on difference scores revealed that groups differed significantly on morbidity/mortality $\quad(F=6.57, \quad \mathrm{df}=3,96$, $\mathrm{P}=0.0005)$ and intervention effectiveness $(F=4.75, \mathrm{df}=3,96, \quad \mathrm{P}=0.003)$. Post hoc Scheffe tests indicated that for the morbidity/mortality knowledge category, the video feedback group had significantly higher scores (mean $=2.1$ ) than the peer feedback group (mean $=0.7$ ) and the control group (mean $=0.3$ ). For intervention effectiveness, the video feedback group had significantly higher scores (mean $=1.5$ ) than the control group (mean $=0.1$ ). No other significant differences were found.
After controlling for pre-test differences, an analysis of covariance revealed significant differences between groups for intervention effectiveness ( $F=5.11$, df $=3,95, P=0.003$ ), with the video feedback group having higher scores than the control group.

\section{PERFORMANCE ON INDIVIDUAL KNOWLEDGE}

ITEMS

Selected individual knowledge items are presented in table 3. For all items shown, changes were in the desired direction. Students' perception of smoking as the single most preventable source of premature mortality increased from $92 \%$ at pre-test to $100 \%$ at post-test. Most students thought doctors could have a significant impact in reducing the number of smokers. Patients' preferred source of assistance for smoking cessation was correctly answered as the patient's doctor by $91 \%$ of students at post-test, compared with $66 \%$ at pre-test.

The proportion of students who indicated that half of all current smokers would like to quit changed from $47 \%$ to $36 \%$ at post-test. Knowledge of the efficacy of the provision of written material to help in quitting increased (from $84 \%$ to $97 \%$ ). Recognition of the positive impact of follow-up visits also increased (from $79 \%$ to $92 \%$ ) as did recognition of the benefits of getting a patient to set a specific quit day (from $82 \%$ to $91 \%$ ). Similarly, more students at post-test (98\%) than at pre-test $(85 \%)$ correctly indicated that physician advice to quit was more effective in patients with a smoking-related illness. Students who incorrectly believed that doctors provide smoking cessation advice to more than three-quarters of their patients decreased from $28 \%$ at pre-test to $12 \%$ at post-test. The proportion of students who incorrectly believed that a doctor's advice to quit would result in a cessation rate of about $40 \%$ increased from $26 \%$ at pre-test to $35 \%$ at posttest. In contrast, the proportion of students who incorrectly believed that doctors detect more than $80 \%$ of their patients who smoke decreased from $35 \%$ at pre-test to $9 \%$ at posttest.

There was an increase in the proportion of students at post-test $(96 \%)$ who recognised the association between smoking and chronic obstructive pulmonary disease compared with pre-test ( $91 \%$ ). At post-test, $86 \%$ of students recognised that risk of death from coronary heart disease in ex-smokers 10 years after cessation was comparable to that of neversmokers, compared with $71 \%$ at pre-test. Knowledge of the risk of cancer of the lung, larynx, and oral cavity was over $95 \%$ at pre-test and, at post-test, knowledge of cancer of the oesophagus and bladder increased to about this level. There were also substantial improvements in knowledge of associations with cancer of the kidney ( $32 \%$ to $58 \%$ ) and the pancreas $(60 \%$ to $77 \%$ ). Knowledge of the association between smoking and increased risk of spontaneous abortion and fetal death rose from $88 \%$ at pre-test to $96 \%$ at post-test. 
Table 4 Smoking attitude scores by group

\begin{tabular}{lcccccc}
\hline \multirow{2}{*}{ Groups } & \multicolumn{2}{c}{ Pre-test } & & \multicolumn{2}{c}{ Post-test } \\
\cline { 2 - 3 } \cline { 5 - 7 } & $\%$ & Mean (SD) & & $\%$ & Mean (SD) \\
\hline Group 1 (control group) & 69 & $43.7(7.25)$ & & 74 & $46.4^{\star}(4.03)$ \\
Group 2 (audio feedback) & 69 & $43.8(3.50)$ & & 71 & $45.0(5.57)$ \\
Group 3 (peer feedback) & 71 & $45.0(4.96)$ & & 69 & $43.8(4.49)$ \\
Group 4 (video feedback) & 67 & $42.5(7.20)$ & & 71 & $44.8(4.54)$ \\
All groups & 69 & $43.9(5.95)$ & & 71 & $45.1(4.67)$ \\
\hline
\end{tabular}

Maximum possible score $=63$.

$\star$ Significantly increased scores at post-test $(\mathrm{P}<0.05)$.

Table 5 Smoking cessation attitude scores. (Figures presented are the aggregate scores from the three end points of the seven-point scales used.) (Three additional questions relating to health promotion are not shown here.)

\begin{tabular}{llll}
\hline & & Pre-test (\%) & Post-test (\%) \\
\hline Q 1 & How difficult is it to help patients to stop smoking? & 80 ("Difficult") & 64 ("Difficult") \\
Q 2 & $\begin{array}{c}\text { I feel that I require further skills in counselling } \\
\text { patients. }\end{array}$ & 76 (Yes) \\
Q 3 & $\begin{array}{c}\text { Smoking, due to its sensitive nature, is difficult to } \\
\text { raise in medical practice. }\end{array}$ & 85 (Disagreed) & 92 (Disagreed) \\
Q 4 & $\begin{array}{c}\text { I believe my efforts overall, as a medical } \\
\text { practitioner, would be worthwhile in changing } \\
\text { patients' smoking habits. }\end{array}$ & 92 (Agreed) & 97 (Agreed) \\
Q 5 & $\begin{array}{c}\text { Other referral agencies or health professionals are } \\
\text { generally better equipped than medical } \\
\text { practitioners to get patients to stop smoking. }\end{array}$ & 30 (Agreed) & 23 (Agreed) \\
Q 6 & $\begin{array}{c}\text { I fear that I would lose patients if I raised the } \\
\text { issue of their smoking. }\end{array}$ & 90 (Disagreed) & 85 (Disagreed) \\
\hline
\end{tabular}

At post-test, most students $(92 \%)$ recognised that nicotine gum was effective for patients who demonstrated high levels of nicotine dependence (up from $78 \%$ at pre-test), with a concomitant decrease in the proportion of students who incorrectly believed that nicotine gum could be used to help a patient cut down the number of cigarettes smoked (92\% to $74 \%$ ).

\section{QUESTIONS ON ANTICIPATED CLINICAL}

BEHAVIOUR

At pre-test $63 \%$ of students stated that they would detect $70 \%$ or more of their smoking patients in everyday clinical practice. At post-test a significantly greater percentage $(82 \%)$ of students claimed that they would detect this proportion of smokers $(t=-3.84$, df $=92, \mathrm{P}=0.0005$ ).

When asked "What percentage of patients do you think you would routinely ask about smoking?", $79 \%$ of the students at pre-test stated that they would ask $70 \%$ or more of their patients, and of these, $45 \%$ reported they would ask all of their patients. There was no significant change at post-test $(t=-1.19$, $\mathrm{df}=91, \mathrm{P}=0.236$ ).

\section{ATTITUDE SCORES}

Mean pre- and post-test attitude scores were calculated for the whole sample (table 4). At pre-test the mean attitude score was 43.9 (range $=16-55$ ), out of a maximum possible score of 63 . The cohort's mean attitude score at post-test was 45.1 (range $=35-56$ ). The change in scores between pre- and post-test was of borderline statistical significance $(t=-1.80, \mathrm{df}=99, \mathrm{P}=0.07)$.

Mean attitude scores for each experimental group were also calculated at pre- and post-test (table 4). A within-groups analysis using paired $t$ tests revealed a significant increase in attitude scores for the control group only $(t=-2.24$, $\mathrm{df}=30, \mathrm{P}=0.03$ ). A between-groups analysis of difference scores found no significant differences $(F=2.17, \mathrm{df}=3,96, \mathrm{P}=0.09)$.

\section{INDIVIDUAL ATTITUDE ITEMS}

Pre- and post-test scores on selected individual attitude items are shown in table 5. In response to the question "How difficult is it to help patients to stop smoking?", at pre-test $80 \%$ of the students indicated that it was difficult, decreasing to $64 \%$ at post-test. When asked to indicate whether further skills were required in counselling patients about how to stop smoking, $96 \%$ of the students felt they required further skills at pre-test compared with $76 \%$ at post-test. Most students at pre-test $(85 \%)$ and at post-test (92\%) disagreed with the statement "Smoking, due to its sensitive nature, is difficult to raise in medical practice." At both pre-test (92\%) and posttest $(97 \%)$, most students indicated agreement with the statement "I believe my efforts overall, as a medical practitioner, would be worthwhile in changing patients' smoking habits."

In response to the statement "Other referral agencies or health professionals are generally better equipped than medical practitioners to get patients to stop smoking", $30 \%$ of the students agreed with the statement at pre-test and $23 \%$ at post-test. At pre-test most students $(90 \%)$ disagreed with the statement "I fear that I would lose patients if I raised the issue of their smoking", whereas at post-test $85 \%$ of the students disagreed with this statement.

\section{RELATIONSHIP BETWEEN KNOWLEDGE AND \\ ATTITUDE SCORES}

Pearson's product moment correlations were used to determine the relationship between students' knowledge and attitude scores. The correlation between knowledge and attitude scores (for all groups combined) was not found to be significant at pre-test $(r=0.11, \mathrm{df}=100$, $\mathrm{P}=0.258)$ or at post-test $(r=0.00, \mathrm{df}=100$, $P=0.983$ ).

\section{Discussion}

Our survey is one of a number of studies undertaken to assess the smoking-related knowledge and attitudes of medical students. $^{5-9}$ Our study also compared the effect of different educational strategies on students' smoking-related knowledge and attitudes. The survey formed part of a larger, randomised, controlled trial investigating a variety of educational strategies to teach senior medical students the skills necessary to successfully offer smoking cessation interventions. $^{30}$

Overall, the smoking-related knowledge of senior medical students was found to be relatively good at pre-test with a significant increase in knowledge achieved following training. It is interesting to note that knowledge levels of this cohort of medical students, even at pre-test, were better than those reported in studies elsewhere. ${ }^{7}$ The positive changes in knowledge achieved in our study were consistent across the four educational modes 
examined. That is, training in general resulted in a positive change in knowledge, and this shift was not dependent on the nature of the educational intervention or mode of delivery. The students also held reasonably positive attitudes with regard to medical practitioner involvement in smoking cessation. Encouragingly, nearly all students believed that doctors could make a significant impact in reducing the number of smokers.

Only $4 \%$ of this sample of senior medical students identified themselves as smokers-a finding consistent with the declining prevalence of smoking among Australian medical practitioners, ${ }^{31}$ and previous studies of Australian medical students. ${ }^{8}$ Indeed after the United States, Australia has been found to have one of the lowest recorded levels of smoking among medical students. ${ }^{7}$ This finding augurs well for the potential involvement of future medical practitioners in smoking cessation activities, as there is evidence that doctors who do not smoke are more likely to offer smoking cessation advice. ${ }^{2}$ Similarly, recent studies of medical students' smoking status and their attitudes towards preventive pulmonary intervention have found non-smokers to be significantly more positive. ${ }^{5}$

\section{EFFECTS OF TRAINING}

On completion of the smoking training programme, all students recognised smoking to be the single most preventable cause of mortality, and most understood the association between smoking and obstructive pulmonary disease and realised the reduced risk of death from heart disease after giving up smoking. Post-test, more students also knew of the association between maternal smoking and the risk of spontaneous abortion and fetal death.

After training, most students came to recognise the low level of frequency with which doctors actually intervened with smoking patients. There was also a substantial increase in students' perception of the proportion of smokers wishing to quit and in students' belief that doctors were patients' first preference for assistance in quitting. In addition, they had a better understanding of the benefit of patient follow-up on cessation rates, and were more knowledgeable about setting specific quit dates and the value of providing written material. Although nearly all students considered smoking intervention to be worthwhile, they did not necessarily believe that it was easy to get patients to quit.

It is noteworthy that about a third of students still had unrealistically high expectations of the cessation rates that could be achieved by medical practitioner intervention. This high expectation persisted even after exposure to the training programmes which specifically addressed the issue of cessation rates that could hope to be achieved. If newly graduating medical practitioners are to become increasingly involved in patients' smoking and more actively involved in smoking cessation activities, then it is important that they have realistic expectations of the success rates that can be anticipated. It has been speculated that one of the main reasons for general practitioners' (GPs') failure to continue smoking cessation interventions is their perception of high "failure" rates and an inadequate understanding of the complex process and inherent phases of behaviour change. ${ }^{1}$ That is, they do not perceive there to be a sufficient success rate to make it worth their while. From a public health perspective, however, the greatest success to be achieved in smoking cessation will result from a large number of GPs, and other medical practitioners, helping a relatively small number of patients to quit. ${ }^{4}$

IMPACT OF DIFFERENT FORMS OF TRAINING

Each of the four educational approaches used in our study resulted in significant increases in knowledge at post-test. However, after controlling for pre-test differences, the groups receiving peer feedback and video feedback and the control group achieved significantly higher scores than the audio feedback group. There is some basis, therefore, to assume that these educational strategies may have resulted in enhanced potency in the learning experience for these students. When we examined knowledge increases on specific knowledge subcategories, we found that significant increases were achieved in the categories for morbidity and mortality and for intervention effectiveness. The former finding is not unexpected; the latter is of more interest. In terms of performance in smoking intervention effectiveness, it was the video feedback group that performed best. This suggests that video feedback may be a superior educational methodology if improvement in areas such as knowledge of clinical effectiveness is desired.

\section{KNOWLEDGE DEFICITS}

Some important knowledge deficits were apparent from our study. For example, $76 \%$ of students at post-test still mistakenly believed that nicotine gum could be used to assist smokers to cut down the amount they smoked. This is a disturbingly high proportion of senior students who misunderstand the nature of nicotine replacement therapy, even after having received smoking cessation training. This result is consistent with findings of previous studies which have reported that medical practitioners often give less than fully accurate advice regarding the use of the gum. ${ }^{32}$ More intensive efforts appear to be needed to address this issue. However, low levels of student knowledge on the correct use of nicotine gum may be less worrisome with the increasing use of nicotine patches.

More importantly, the greatest knowledge deficits were found in relation to intervention strategies and cessation practices that are recommended to assist someone to quit. When we examined knowledge levels on four categories of questions, we found that on average, students achieved higher scores at post-test on items relating to morbidity and mortality questions and on intervention effectiveness. Performance levels on cessation practices and intervention strategies, however, were substantially lower. Despite post-test improvement, 
performance levels for these pivotal areas remained relatively low. Although it is relatively easy to improve knowledge levels with respect to the burden of illness associated with smoking, it is more difficult, yet more important, to address future medical practitioners' knowledge of how to intervene.

There are important implications of this finding for future training programmes. Specifically, the importance of ensuring that adequate attention is directed to knowledge of the specific skills required to give appropriate smoking cessation advice and counselling is highlighted. Such an approach goes well beyond a knowledge base which focuses on the facts and figures of the prevalence of tobacco use and its morbid consequences. Without an understanding of the effective strategies required to address smoking cessation with patients, and the enhanced levels of self-efficacy which often accompany this, doctors will remain hampered in their efforts and motivations to engage patients in smoking cessation.

This latter finding underscores the need for future training programmes to place greater emphasis on the actual components of intervention. Attention is also drawn to the findings of the skills component of this study, ${ }^{30}$ which found significantly improved smoking cessation skills for all three forms of interactive training (involving feedback techniques) compared with no improvement with didactic teaching methods. If future medical practitioners are to engage actively and appropriately in offering patients smoking cessation advice and counselling, it is imperative that they acquire the skills and knowledge base fundamental to this task. It is pertinent to note that Ockene has previously found that "physicians often report not intervening with smokers because they do not know what to instruct them to do" (page 1044). ${ }^{29}$ Clearly, until suitable training is provided at both the undergraduate and continuing medical education (CME) levels, clinicians' ability to intervene effectively will remain substantially impaired.

\section{SMOKING-RELATED ATTITUDES}

Most students were confident about their ability to detect and intervene with smokers in clinical practice. They perceived smoking intervention to be worthwhile, and believed that they would routinely ask most of their patients about smoking. In general, they did not think smoking cessation was a difficult issue to raise in a consultation, and, as has been found in other studies, they did not fear that raising this topic would cause them to lose patients. $^{22}$

However, the students were pessimistic about the ease with which patients' smoking behaviour could be changed, and at post-test, nearly a quarter of students believed that other referral agencies or health professionals were generally better equipped than medical practitioners to deal with smoking cessation. In addition, although twice as many students, after receiving training, saw assisting patients to quit smoking as "easy", more than $60 \%$ of students still ascribed the task as possessing a degree of difficulty. Clearly, a perception exists among many medical students that smoking remains a demanding, if not an intractable, behaviour to alter. For future doctors to be more positively disposed to involvement in smoking intervention, a more optimistic, yet still realistic, perspective is important.

Students' estimates of doctors' skills in detecting patients who are smokers were more realistic following training. However, about a third of students at both pre- and post-test held inflated views about the impact of a doctor's advice to quit smoking. Instilling accurate and realistic perceptions of the potential impact that interventions can have on cessation rates is fundamental to ensure that future medical practitioners are not disillusioned about their role in smoking cessation.

\section{STUDENTS' PERCEPTIONS OF THE NEED FOR} TRAINING

A slightly disconcerting finding was that following only three hours of instruction in smoking cessation intervention and counselling strategies, approximately one in four students felt they needed no further skills training in counselling patients about stopping smoking, compared with only $4 \%$ at pre-test. Although increased confidence in this area is to be encouraged, it would be unfortunate if, after only a short training period, senior medical students were imbued with a false sense of confidence regarding their smoking intervention and counselling skills. The data on the skills assessment component of our study ${ }^{30}$ indicate that, although significant improvements in clinical practice skills were achieved at post-test for all experimental groups, performances still fell far below a minimum level of competence for appropriate smoking cessation intervention. Future training programmes may be well advised to inoculate students against an unwarranted sense of competence in this complex area of behaviour change after receiving only a modest level of training.

\section{A PUBLIC HEALTH PERSPECTIVE}

Although it has been argued that doctors are limited in what they can do on their own, ${ }^{26}$ they are nonetheless well placed to contribute significantly to the challenging process of smoking cessation. However, it is evident that more needs to be done to show future doctors that, although their success rate with individual patients may seem small, it is, nonetheless, extremely important in public health terms.

To achieve further successes in smoking cessation, it is vital that there be a resonance between the cultural, political, and economic environments. It is therefore important that future doctors be suitably trained to participate in this process, so they may contribute to the challenge of smoking cessation and make optimal use of the plethora of opportunities for intervention in clinical practice.

1 Richmond RL, Anderson P. Research in general practice for smokers and excessive drinkers in Australia and the UK dissemination of interventions. Addiction 1994;89:49-62. 
2 Wells KB, Lewis CE, Leake B, et al. The practices of general and subspeciality internists in counseling about smoking and exercise. Am $\mathcal{F}$ Public Health 1986;76:1009-13.

3 Goldstein MG. Nicotine dependence. The Project ADEPT curriculum for primary care physician training. In: Dube $\mathrm{C}$, Goldstein MG, Lewis DC, Myers ER, Zwick WR, eds. Providence, Rhode Island: Project ADEPT, Brown University, 1989.

4 Lowe JB, Del Mar C. Increasing the numbers of general practitioners who provide smoking cessation advice. Med $f$ Aust 1992;156:294-5.

5 Frye AW, Haponik EF. Medical students' smoking history and their preventive pulmonary attitudes. $A m \mathcal{F}$ Prev $M e d$ 1996;12:4.

6 Derman U, Demir G, Akan P. Is awareness of its risk enough to stop people from smoking? $\mathcal{F}$ Cancer Educ 1995;10:68 70

7 Crofton JW, Freour PP, Tessier JF. Medical education on tobacco: implications of a worldwide survey. Med Educ 1994;28:187-96

8 Tessier JF, Freour P, Belougne D, Crofton J. Smoking habits and attitudes of medical students towards smoking and antismoking campaigns in nine Asian countries. Int $\mathscr{f}$ Epidemiol 1992;21:298-304.

9 Kory WP and Crandall LA. Nonmedical drug use pattern among medical students. Int $\mathcal{F}$ Addict 1984;19:871-84

10 Dekker HM, Looman CWN, Adriaanse HP, Van Der Maas PJ. Prevalence of smoking in physicians and medical students, and the generation effect in the Netherlands. Soc Students, and the generation

11 Yaacob I, Abdullah ZA. Smoking behavior, knowledge and opinion of medical students. Asia-Pacific $\mathcal{f}$ Public Health 1994;7:88-91.

12 Forney PD, Forney MA, Fischer P, et al. Sociocultural correlates of substance use among medical students. $f$ Drug Educ 1988;18:97-108.

13 Baldwin DC, Hughes PH, Conard SE, Storr CL, Sheehan DV. Substance use among senior medical students. $\mathscr{f} A M A$ 1991;265:2074-8.

14 Vlajinac $H$, Adanja B, Jarebinski $M$. Cigarette smoking among medical students in Belgrade related to parental smoking habits. Soc Sci Med 1989;29:891-4.

15 Nelson DE, Giovino GA, Emont SL, et al. Trends in cigarette smoking among US physicians and nurses. fAMA 1994;271:1273-5.

16 Nachtigal D, Rishpon S, Epstein LM. Smoking among medical and engineering students. Med Educ 1989; 23:196-200.

17 Tessier JF, Fréor PP, Nejiari C, et al. Smoking behaviour and attitudes of medical students towards smoking and anti-smoking campaigns: a survey of 10 African and Middle Eastern countries. Tobacco Control 1992;1:95-101.

18 Tessier JF, Fréor PP, Nejjari C, et al. Smoking behaviour and attitudes towards smoking of medical students in Australia, Japan, USA, Russia, and Estonia. Tobacco Control 1993;2:24-9.

19 Mullins R, Borland R. Doctors' advice to their patients about smoking. Aust Fam Physician 1993;22:1146-55.

20 Kottke TE, Battista RN, DeFriese GH, Brekke MI Attributes of successful smoking interventions in medical practice: a meta-analysis of 39 controlled trials. $7 A M A$ 1988;259:2883-9.

21 Cummings SR, Stein MJ, Hansen B, Richard RJ, Gerbert B, Coates TJ. Smoking counseling and preventive medicine. A survey of internists in private practices and a health maintenance organisation. Arch Int Med 1989;149:345-9.

22 Dickinson JA, Wiggers J, Leeder SR, Sanson-Fisher RW. General practitioners' detection of patients' smoking status. Med $¥$ Aust 1989;150:420-6.

23 Hill D, Borland R. Are doctors doing enough to stop their patients smoking? Med f Aust 1989;150:413-14.

24 Weller DP, Litt JCB, Pols RG, Ali PL, Southgate DO, Harris $\mathrm{RD}$. Drug and alcohol related health problems in primary care: What do GPs think? Med $\neq$ Aust 1992 156:43-8.

25 Wechsler H, Levine S, Idelson RK, Rohman M, Taylor JO The physician's role in health promotion. $N$ Engl $f \mathrm{Med}$ 1983;43:939-55.

26 Chapman $S$. The role of doctors in promoting smoking cessation. BMF 1993;307:518-9.

27 Kenney RD, Lyles MF, Turner RC, et al. Smoking cessation counseling by resident physicians in internal medicine family practice and pediatrics. Arch Int Med 1988. 148:2469-73.

28 Kottke TE, Willms DG, Solberg LI, Brekke ML. Physician delivered smoking cessation advice: issues identified during ethnographic interviews. Tobacco Control 1994; 3:46-9.

29 Ockene JK. Physician-delivered intervention for smoking cessation: Strategies for increasing effectiveness. Prev Med 1987;16:723-37.

30 Roche AM, Eccleston P, Sanson-Fisher R. Teaching smoking cessation skills to senior medical students: A block-randomized controlled trial of four different approaches. Prev Med 1996;25:251-8.

31 Magnus P. Cigarette smoking and the medical profession. Med $\mathcal{F}$ Aust 1989;150:437-41.

32 Cummings SR, Hansen B, Richard RJ, Stein MJ, Coates TJ Internists and nicotine gum. $\mathfrak{f} A M A$ 1988;260:1565-9.

\section{Tobacco in history}

"[L]ike all other narcotics its excessive use or abuse must impair the health and engender disease. Of the different modes of using tobacco, it is probable that smoking is the most injurious, and the most capable of abuse, since in this process the active principles of the tobacco are volatilized with the smoke, and are extensively applied to the lungs as well as the mouth and nose and fauces. ... Notwithstanding the common use and extensive consumption of tobacco in its various forms, it must unquestionably be ranked among narcotic poisons of the most active class."

(Bigelow J. Nature in disease, illustrated in various discourses and essays, to which are added miscellaneous writings, chiefly on medical subjects. Boston: Ticknor and Fields, 1854:323-36. Submitted by Dr Stephen Jay.) 